\title{
On Understanding the Methodologies adopted in KMS Studies within the Context of Quality Strategy
}

\author{
Mohammad Fakhrul Nizam, Mohammad*¹, Rusli, Abdullah², Marzanah A Jabar ${ }^{3}$, Rozi Nor, Haizan Nor ${ }^{4}$ \\ ${ }^{1}$ Universiti Kuala Lumpur, Kuala Lumpur, Malaysia \\ ${ }^{1,2,3,4}$ Faculty of Computer Science and Information Technology,Universiti Putra Malaysia, Selangor, Malaysia \\ ${ }^{1}$ fakhrulnizam@outlook.com
}

Article History: Received: 10 November 2020; Revised: 12 January 2021; Accepted: 27 January 2021; Published online: 05 April 2021

\begin{abstract}
In the past, quite number of studies conducted acknowledges the imperative roles of knowledge in supporting quality strategies among organizations, as well as enhancing their competitive advantage.In accordance withthe benefits, organizations establishedan information technology (IT) system to facilitate proper dissemination, creation and management of knowledge. Establishment of knowledge management system (KMS) indicates the important inclusion of technical and socio aspects.Past academic studies focus on establishment of KMS have been conducted with various objectives, strategy and scope. As always, establishment of KMS as a platform for knowledge management does require structured and systematic methodology. Hence, the objective of this study is to unwrap the approaches and methodologies undertaken by past studies in relation to KMS establishment within the quality strategy context. As such, review of past articles published a decade agowere conducted and analysed. Past articles were retrieved from various established journals such as Emerald, Science Direct, Journal of the Association for Information Systems (AIS), Association for Computing Machinery (ACM) as well as Google Scholar database and were verified with SCOPUS journal database to ensure its integrity. Review of past articles discovered several findings that contribute to gap fulfilment of the research in future.
\end{abstract}

Keywords: Adopted methodology, quality strategy, knowledge management, article review

\section{Introduction}

Use of IT system has changed the way how businesses are conducted and managed today. In the past, IT system has been regarded as business enabler; but its roles have been further expanded nowadays. With the objective to remain sustainable in a competitive market as well as to manage organizations' costs and operations wisely, adoption of IT system in today's situation are more towards leading and driving the organizations' strategy. In organization, the existence of knowledge assets such as input, output and processes are important and significant in moderating the process of knowledge creation within (Lin \& Wu, 2005). In fact, knowledge has been acknowledge as a precious asset in optimizing the competitive advantage of organizations (Halawi, Aronson, \& McCarthy, 2005). In another context, proper mapping of knowledge activities with organization's strategy has helped them to be more competitive(Chikati \& Mpofu, 2013). Hence, organization shall reapthe benefits from proper knowledge management (KM). A study byChua (2004)has suggested that proper KMwithin organizations requires three factors such as social, economic and technology aspects. As such, adoption of technology such as IT system is needed as a platform to support activities of KM such as knowledge acquisition, creation, sharing and storing(Alavi \& Leidner, 2001; Ansari Ch., Khobreh, Nasiri, \& Fathi, 2009; Hussain et al,. 2017; Kuo, Ming-Fong, \& Lee, 2011; Talebi, Rezayi, Gholizadeh, Heidarian, \& Zanjani, 2012). On top of that, proper implementation of $\mathrm{KM}$ within organization has helped them to intensify quality strategies in their organization. For instance, studiesconducted by Wilson \& Campbell (2018) and Wilson \& Campbell (2016)indicated that both knowledge management and quality standards are complementing to each other.

Establishment of KMS as a platform to support KM in organization specifically to intensify and support quality strategies have been conducted by many studies in the past. This is aligned with the objective of KMSitself which is to ensure deliveries of knowledge at the right time, with the right tools to the right people. Based on past reviews, establishment of KMS has been developed usingseveral methodologies, strategies and objectives. In fact, there were difficulties reported in establishing effective KM in organization due to the scarcity of accurate methodologies used to outline the establishment and implementation of KMS (Chalmeta \& Grangel, 2008).As an example, although more organizations are interested with the use of Web 2.0 tools for KMS implementation, but there were several weaknesses with the methodologies used to support the establishment of Web 2.0 based KMS (known as KMS 2.0) in addressing the needs of organizations(Chalmeta \& Grangel, 2017) and (Hussain et al., 2017a). Based on Chalmeta \& Grangel (2017) as well, weaknesses of existing methodologies to support Web 2.0 capabilities can be due to many factors; one of it such as use of nonpractical methodologies that are either too theoretical or never practically implemented. Therefore, it is greatly important to understand methodologies applied by past studies in the establishment of KMS within the quality strategy context. 


\section{Materials and Methods}

In achieving the objective of this study, literature search has been conducted by retrieving articles from journal databases such as Emerald, Science Direct, AIS, ACM and Google Scholar. In assuring the quality of all articles retrieved, articles retrieved from identified database were cross-checked with SCOPUS database list extracted from webpage http://scimagojr.com. In narrowing the search focus of the articles, only articles published within a decade ago from the year 2009 till 2019 related with establishment of knowledge management system as a mechanism to intensify quality strategy and management within organization were retrieved. As a result, a total of 69 articles have been identified as related to the scope of this study and analysed. Each of the article were analysed by skimming through and identifying the objective of the study and methodologies adopted. For easier reference, each of the article is also numbered with individual paper identification (labelled as Article ID).In analysingall articles, two areas within the past study has been reviewed and assessed attentivelywhich are scope of study and adopted methodologies.

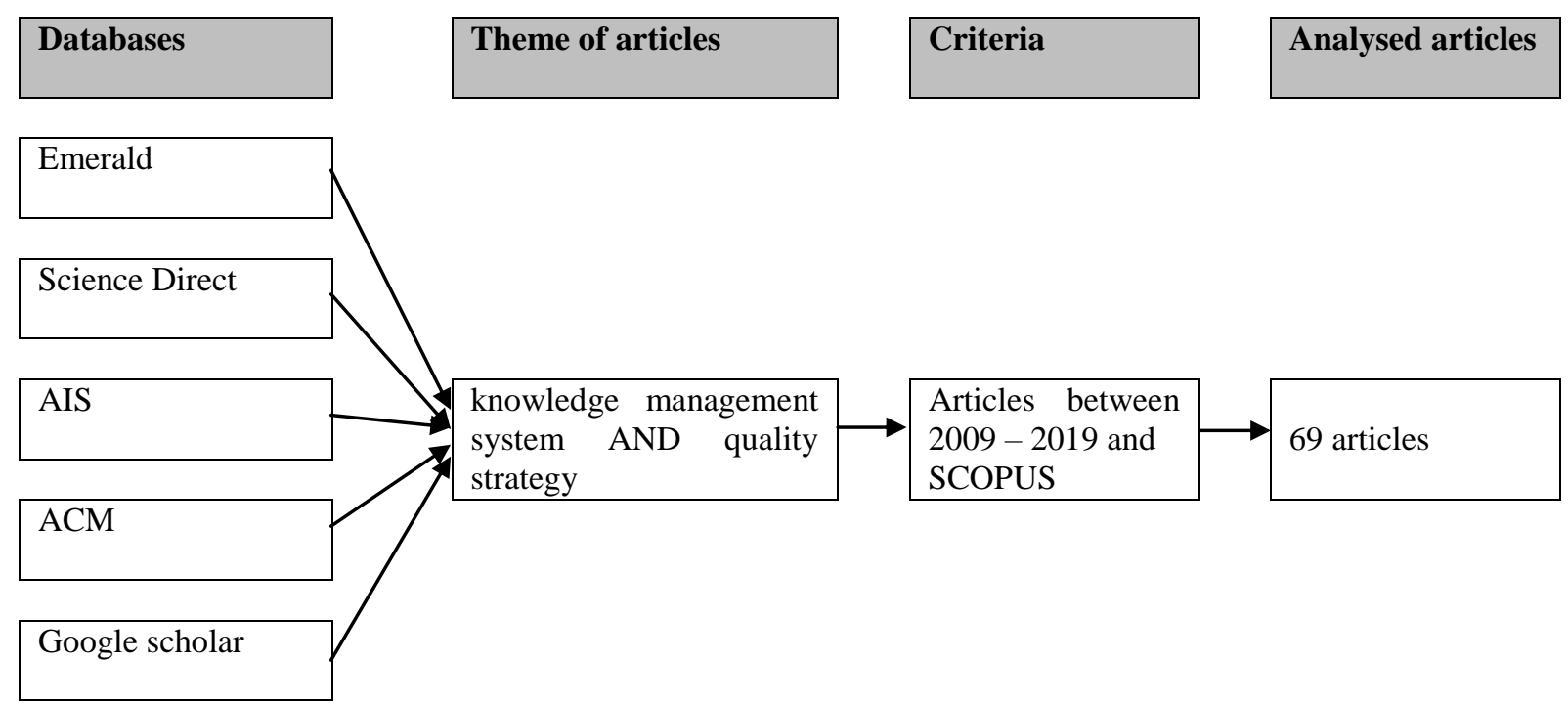

Figure 1. Extraction of articles from databases for the analysis

\section{Results and Discussion}

By adopting the above methodology, related articles have been retrieved from the database and analyzed as shown in Table 1.Based on the analysis of the articles, scope of studies can be classified into 12 categories; of which the top three categories with the highest number of articles were related to (a) development, design or evaluation of IT system, database, prototype or tools (19 articles), (b) Investigation on the impact of IT System or KMS on dependent variables such as quality and performance enhancement (11 articles) and (c) investigation on the roles, effects or concepts of certain dimensions or variables (10 articles). Hence, based on the classification on the scope of study from those articles, it can be concluded that majority of the interest of past authors on KMS studies within the context of quality strategy and initiatives in organization are more towards its establishment, designing or evaluation of the existing system. This finding is aligned with the systematic review study conducted by Iskandar, Jambak, Kosala, \& Prabowo (2017) that stated the top three issues discussed related to future KMS research were on the development of KMS itself such as the growing needs for KMS capabilities and features, adoption of Big Data in KMS and adoption of new technology for KMS.

Meanwhile, information listed in

Table 2 indicated on methodologies adopted by past authors in conducting studies from the articles; suggested that the top four highest methodologies used in conducting KMS related studies within the quality strategy context were through (a) cross sectional survey (25 articles), (b) empirical study and structured equation modelling (SEM) (11 articles), (c) case studies (11 articles) and (d) use of other types of tools and methods in KMS such as Analytic Hierarchy Process (AHP), Quality Function Diagram (QFD), Fuzzy Linguistic, Semantic Wiki tool (SWM), Business Intelligence Index, KM Framework and Hybrid Uncertain Programming (HFICP) modelten articles. On top of these, it is also discovered that most of the articles were adopting more than one methodology in their studies. 
Table 1. Scope of past studies

\begin{tabular}{|c|c|c|c|}
\hline NO & SCOPE OF STUDY & $\begin{array}{l}\text { TOTAL } \\
\text { ARTICLES }\end{array}$ & ARTICLE ID \\
\hline 1 & $\begin{array}{l}\text { Development \Design \Evaluation of System \Database } \backslash \\
\text { Ontology based system } \backslash \text { Prototype } \backslash \text { Tool }\end{array}$ & 19 & $\begin{array}{l}1,18,19,26,28,32,36,38, \\
40,41,42,46,50,51,53,54, \\
62,63,68\end{array}$ \\
\hline 2 & $\begin{array}{l}\text { Embedment I Integration of Artificial Intelligent (AI) } \\
\text { Development Intelligent System Fuzzy }\end{array}$ & 3 & $12,47,58$ \\
\hline 3 & Development of frameworks & 4 & $55,64,65,67$ \\
\hline 4 & Development of model & 5 & $3,5,8,21,22$ \\
\hline 5 & Correlation \Relationship & 1 & 50 \\
\hline 6 & $\begin{array}{l}\text { Investigation on the roles, effects or concepts of } \\
\text { dimensionslvariables }\end{array}$ & 10 & $\begin{array}{l}6,9,10,12,13,15,16,17 \\
49,66\end{array}$ \\
\hline 7 & $\begin{array}{l}\text { Alignment \ Extraction \ Simulation I Investigation of } \\
\text { knowledge } \backslash \text { flow } \backslash \text { components in IT systems } \text { software }\end{array}$ & 4 & $7,24,27,44$ \\
\hline 8 & $\begin{array}{l}\text { Investigation on impact of IT System\KMS on dependent } \\
\text { variables (quality, performance enhancement) }\end{array}$ & 11 & $\begin{array}{l}2,11,20,23,29,30,31,39 \\
43,48,56\end{array}$ \\
\hline 9 & $\begin{array}{l}\text { Investigation I impact I identification of independent } \\
\text { variables on knowledge components }\end{array}$ & 4 & $45,57,59,60$ \\
\hline 10 & $\begin{array}{l}\text { Integration } \backslash \text { investigation of two different management } \\
\text { systems } \backslash \text { domain }\end{array}$ & 4 & $4,33,37,52$ \\
\hline 11 & $\begin{array}{l}\text { Investigation on concepts of Decision Making I Expert } \\
\text { Systems }\end{array}$ & 3 & $14,25,69$ \\
\hline 12 & Guidelines for software development & 1 & 35 \\
\hline
\end{tabular}

Table 2. Types of methodology applied

\begin{tabular}{|c|c|c|c|}
\hline NO & TYPES OF METHODOLOGY APPLIED & $\begin{array}{l}\text { TOTAL } \\
\text { ARTICLES }\end{array}$ & ARTICLE ID \\
\hline 1 & Empirical \Structural Equation Modelling (SEM) & 11 & $\begin{array}{l}21,31,40,42,43,44,45 \\
48,56,65,66\end{array}$ \\
\hline 2 & Environment Diagram i.e Case Diagram & 1 & 1 \\
\hline 3 & Develop \Design of IT Systems \Software & 8 & $1,7,12,18,46,47,62,67$ \\
\hline 4 & Development of simulation $\backslash$ research model & 2 & 24,48 \\
\hline 5 & Prototype implementation & 1 & 21 \\
\hline 6 & Cross Sectional Survey & 25 & $\begin{array}{l}2,3,5,12,13,16,17,23,27, \\
28,29,31,40,43,45,48, \\
49,56,57,58,60,62,64, \\
65,66\end{array}$ \\
\hline 7 & Longitudinal study & 1 & 11 \\
\hline 8 & Hypotheses $\backslash$ Correlation testing & 4 & $5,43,65,66$ \\
\hline 9 & $\begin{array}{l}\text { Use of models, tools, methods i.e Analytic Hierarchy } \\
\text { Process, Quality Function Diagram, Fuzzy Linguistic, } \\
\text { Semantic Wiki tool, Business Intelligence Index, KM } \\
\text { Framework, Hybrid Uncertain Programming (HFICP) } \\
\text { model. }\end{array}$ & 10 & $\begin{array}{l}6,7,25,34,40,51,53,61, \\
62,68\end{array}$ \\
\hline 10 & Qualitative - Interview \Expert review & 6 & $2,20,39,52,56,58$ \\
\hline 11 & Qualitative - Workshop \Focus Group & 3 & $4,6,7$ \\
\hline 12 & Qualitative - Case study & 11 & $\begin{array}{l}19,32,36,39,42,51,54,59, \\
61,62,69\end{array}$ \\
\hline 13 & Mixed method - Quantitative and Qualitative & 1 & 8 \\
\hline 14 & Process mapping approach & 1 & 9 \\
\hline 15 & Literature $\backslash$ Document Review & 7 & $10,14,22,27,33,37,42$ \\
\hline 16 & Participative enquiry approach & 1 & 19 \\
\hline 17 & Action research & 4 & $19,34,52,67$ \\
\hline 18 & System modelling technique $\backslash$ Prototype testing & 2 & 22,61 \\
\hline 19 & $\begin{array}{l}\text { IDEFO (Integrated Computer Aided Manufacturing for } \\
\text { Function Modelling) }\end{array}$ & 2 & 22,55 \\
\hline 20 & Past studies approach $\backslash$ steps $\backslash$ methods $\backslash$ guidelines & 1 & 26 \\
\hline 21 & TRIZ (Theory of Inventive Problem Solving) & 1 & 30 \\
\hline
\end{tabular}




\begin{tabular}{|l|l|l|l|}
\hline NO & TYPES OF METHODOLOGY APPLIED & $\begin{array}{l}\text { TOTAL } \\
\text { ARTICLES }\end{array}$ & ARTICLE ID \\
\hline 22 & Theoretical model testing & 2 & 31,40 \\
\hline 23 & OQL (Ontology Web Language) & 1 & 32 \\
\hline 24 & Joint Variance Analysis method & 1 & 33 \\
\hline 25 & Experiments & 2 & 35,63 \\
\hline 26 & Defining expert profile \structure & 1 & 38 \\
\hline 27 & Access and use of secondary data & 1 & 39 \\
\hline 28 & Association rule method & 1 & 51 \\
\hline 29 & Development of measurement item & 2 & 56,58 \\
\hline 30 & Extraction of knowledge objects from database & 1 & 65 \\
\hline 31 & Not stated with methodology & 1 & 15 \\
\hline
\end{tabular}

\section{Conclusion}

Studies on IT system establishment such as KMS has always attracted major focuses in academic research for its application and adoption within the real environment. From the context of information system (IS) studies, it is undeniably agreed that the major interest remain on the development and designing of the system. However, it is also discovered that in adopting to new requirement and challenges, studies on KMS establishment has also attracted focus of past authors to concentrate on the integration of IT system with tools and methods such as multicriteria decision making tools (such as AHP), business intelligence and artificial intelligence tools (such as Fuzzy Logic). However, one of the significant finding from the study is that there is lack of interest among past studies either on the development of framework (only four articles) or model (five articles). Development of framework or model is essential in establishing solid IT system since any setback that may occur in the system implementation will contributed to the costs implication to organization (Sinha, Arora, \& Mishra 2012; YuChung, Shi-Ming, Lin, Quo-Pin, \& Mei-Ling-Tsai 2005).

Thus, the above finding on past studies conducted is hoped will assist future researcher in identifying scope and methodologies adopted to be conducted as a direction for more comprehensive studies within KM and quality domain. Nonetheless, as a quote says, "there is no one size of shoes that fits all", it same goes with the coverage of this study. One of the limitations of this study was that the analysis of the articles was done from countable databases known related to the domain of information system (IS) research. In future, it is suggested that more related databasesor journals will be taken into consideration while conducting the similar scale of study. At the same, the integrity and quality of the articles retrieved were all checked based on the journal of the articles within the SCOPUS database journal up to the year 2019 only. Therefore, there will be tendencies that some of the latest articles may not be included within the scoping criteria set forth for this study. As such, similar types of studies need to be conducted in future. Future research may also consider other types of methodologies as listed in

Table 2 to provide more rigor and varieties of result and outcome of KMS related studies in other areas or disciplines.

\section{References}

1. Alavi, M., \& Leidner, D. E. (2001). Review: Knowledge Management and Knowledge Management Systems Conceptual Foundations and Research Issues. MIS Quarterly, 25(1), 107136.

2. Ansari Ch., F., Khobreh, M., Nasiri, S., \& Fathi, M. (2009). Knowledge Management support for Quality Management to achieve higher customer satisfaction. 2009 IEEE International Conference on Electro/Information Technology, 78-83. https://doi.org/10.1109/EIT.2009.5189588

3. Chalmeta, R., \& Grangel, R. (2008). Methodology for the Implementation of Knowledge Management Systems. Journal of the American Society for Information Science and Technology, 59(5), 742-755. https://doi.org/10.1002/asi

4. Chalmeta, R., \& Grangel, R. (2017). Methodology for the Implementation of Knowledge Management Systems. Business \& Information Systems Engineering. https://doi.org/10.1002/asi.v59:5

5. Chikati, R., \& Mpofu, N. (2013). Developing sustainable competitive advantage through knowledge management. International Journal of Scientific and Engineering Research, 2(10), 7781. 
6. Chua, A. (2004). Knowledge management system architecture: A bridge between KM consultants and technologists. International Journal of Information Management, 24(1), 87-98. https://doi.org/10.1016/j.ijinfomgt.2003.10.003

7. Halawi, L. A., Aronson, J. E., \& McCarthy, R. V. (2005). Resource-based view of knowledge management for competitive advantage. The Electronic Journal of Knowledge Management, 3(2), 75-86. Retrieved from http://www.ejkm.com/issue/download.html?idArticle=55

8. Hussain, A., Mkpojiogu, E.O.C., Jamaludin, N.H., Moh, S.T.L. (2017). A usability evaluation of Lazada mobile application. AIP Conference Proceedings, 1891, art. no. 020059.

9. Hussain, A., Mkpojiogu, E.O.C., Almazini, H., Almazini, H. (2017a). Assessing the usability of Shazam mobile app. AIP Conference Proceedings, 1891, art. no. 020057.

10. Iskandar, K., Jambak, M. I., Kosala, R., \& Prabowo, H. (2017). Current Issue on Knowledge Management System for future research: a Systematic Literature Review. Procedia Computer Science, 116(Iccsci), 68-80. https://doi.org/10.1016/j.procs.2017.10.011

11. Kuo, R.-Z., Ming-Fong, L., \& Lee, G.-G. (2011). The impact of empowering leadership for KMS $\begin{array}{llll}\text { adoption. } & \text { Management } & \text { 49(7), } & \text { 1120-1140. }\end{array}$ https://doi.org/http://dx.doi.org.turing.library.northwestern.edu/10.1108/00251741111151172

12. Lin, C., \& Wu, C. (2005). A knowledge creation model for ISO 9001: 2000. Total Quality Management and Business https://doi.org/10.1080/14783360500077625

13. Sinha, P., Arora, M., \& Mishra, N. (2012). Framework for a Knowledge Management Platform in Higher Education Institutions. International Journal of Soft Computing and Engineering, 2(4), 96100. Retrieved from http://www.ijsce.org/attachments/File/v2i4/D0895072412.pdf

14. Talebi, B., Rezayi, R., Gholizadeh, K., Heidarian, B., \& Zanjani, S. (2012). Ranking Effective Factors on Knowledge Management system in Bonab Islamic Azad University. Life Science Journal, 9(4), 3652-3658.

15. Wilson, J. P., \& Campbell, L. (2016). Developing a knowledge management policy for ISO 9001: 2015. Journal of Knowledge Management, 20(4), 829-844. https://doi.org/10.1108/JKM-11-20150472

16. Wilson, J. P., \& Campbell, L. (2018). ISO 9001 : 2015 : the evolution and convergence of quality management and knowledge management for competitive advantage. Total Quality Management, 1-16. https://doi.org/10.1080/14783363.2018.1445965

17. Yu-Chung, Shi-Ming, H. ;, Lin, H., Quo-Pin, \& Mei-Ling-Tsai. (2005). Critical factors in adopting a knowledge management system for the pharmaceutical industry. Industrial Management \& Data Systems, 105(12), 164-183. https://doi.org/10.1108/02635570510583307 